\title{
O LABORATÓRIO DE QUÍMICA COMO LÓCUS DE EXPERIÊNCIAS FORMATIVAS'
}

\author{
Vânia Gomes Zuin*
}

Antônio Álvaro Soares Zuin**

RESUMO: O laboratório de Química, em muitas ocasiões, ainda é considerado um espaço onde prevalece a noção de que suas práticas deveriam ser autossuficientes, de tal maneira que sua produção seria descontextualizada em relação às determinações socioculturais que as geraram. Mas e se o próprio laboratório, com especial atenção ao de ensino, fosse identificado como um local onde os estudantes seriam estimulados a relacionar as práticas experimentais com tais características, de modo que o raciocínio crítico sobre tal relação fosse promovido e, portanto, fomentadas experiências formativas? Fundamentados principalmente nos escritos de Theodor Adorno e Walter Benjamin, os autores têm, como principal objetivo e contribuição ao campo, argumentar que o laboratório pode ser caracterizado como lócus de desenvolvimento de experiências formativas por meio da transformação do pensamento e ações sócio-historicamente situadas.

Palavras-Chave: Laboratório de ensino. Ensino Superior. Experiências formativas. Teoria Crítica. Escola de Frankfurt.

\section{THE CHEMISTRY LABORATORATORY AS LOCUS OF FORMATIVE EXPERIENCES}

ABSTRACT: The Chemistry laboratory very frequently is still considered a place where the notion that its practices should be self-sufficient prevails, in such a way that its production would be decontextualized in relation to the socio-cultural determinations that generated them. But if the laboratory itself with special attention to teaching could be identified as a place where students would be encouraged to relate experimental practices to these characteristics, so that the critical reasoning about such relationship would be encouraged and, thus promoting formative experiences? Based mainly on Theodor Adorno and Walter Benjamin, the main objective and contribution to the field are to discuss that the laboratory can be characterized as a locus for the development of such formative experiences through the sociohistorical transformation of thought and action.

Key-words: Teaching laboratory. Higher Education. Formative experiences. Critical Theory. Frankfurt School. 


\section{EL LABORATORIO DE QUÍMICA COMO LOCUS DE EXPERIENCIAS FORMATIVAS}

RESUMEN: El laboratorio de Química, en muchas ocasiones, todavía es considerado un espacio donde prevalece la idea de que sus prácticas deberían ser autosuficientes, pero, si así fuera, su producción sería descontextualizada con respecto a las determinaciones socioculturales que las generaron. Sin embargo, ¿y si el propio laboratorio, con especial interés en la enseñanza, fuese reconocido como un sitio donde los estudiantes fuesen estimulados a relacionar las prácticas experimentales con esas características, de modo que el raciocinio crítico acerca de tal relación fuese fomentado y, por lo tanto, fuesen incentivadas experiencias formativas? Basándose primordialmente en los escritos de Theodor Adorno e Walter Benjamin, los autores tienen como principal objetivo y contribución al campo argumentar que el laboratorio puede ser caracterizado como locus de desarrollo de experiencias formativas por medio del cambio del pensamiento y acciones socio-históricamente contextualizadas.

Palabras Clave: Laboratorio de enseñanza. Educación Superior. Experiencias formativas. Teoría Crítica. Escuela de Frankfurt. 


\section{INTRODUÇÃO}

O conceito de experiência, de certa forma, pôde ser observado desde os primórdios da concepção de ciência moderna. Quando Bacon (1561-1626) estabeleceu os princípios epistemológicos de seu Novum Organum, justamente com o objetivo de compreender o modo como se desenvolvia o chamado alfabeto da natureza, ele enfatizou a necessidade da realização de experimentos para a promoção de tal conhecimento. Para além do denominado silogismo aristotélico, cujo valor fora reconhecido pelo próprio Bacon visando exercitar o raciocínio, era preciso fazer com que o pensamento objetivado produzisse algo considerado útil. O sugestivo subtítulo do livro de Bacon: Novum Organum "verdadeiras indicações acerca da interpretação da natureza", já mostrava a importância da realização de experimentos, cuja análise dos resultados possibilitaria produzir não só as leis dos fenômenos naturais, como também a produção de objetos. Esses objetos teriam características distintas de suas origens naturais, de tal forma que novas naturezas seriam confeccionadas. Se, por um lado, Bacon considerava o silogismo aristotélico válido para o exercício do raciocínio, por outro lado, o filósofo empirista inglês o considerava infrutífero, justamente porque as conclusões silogísticas já estavam contidas nas premissas anteriores, tal como no conhecido exemplo: todo homem é mortal. Se Sócrates é homem, então ele é mortal. Mas, sobretudo com o objetivo de se fazer com que a imortalidade do conhecimento humano prevalecesse sobre a fragilidade do próprio ser humano, Bacon, já na epígrafe da primeira edição do Novum Organum, sentenciava que os seres humanos passariam, mas a ciência permaneceria (1973).

De lá para cá, o conhecimento e a produção obtidos mediante o empreendimento tecnocientífico transformou o ser humano em uma espécie de Deus ex Machina, haja vista o atual desenvolvimento da interface entre áreas como a nanotecnologia, a engenharia genética e a computação. A atual produção de chips orgânicos permite vislumbrar uma forma de relação ser humano-máquina talvez apenas imaginada nos romances de ficção científica. Diante de tal quadro, não por acaso disseminam-se preocupações éticas a respeito das consequências do desenvolvimento científico no cotidiano das relações humanas (SCHANK, KRAJCIK, YUNKER, 2007). Santos (2003) ressalta que, quando os seres humanos pressupõem o máximo controle sobre as leis da natureza, rompe-se o limite entre a humanidade e naturalidade desta, por meio da mecanização dos próprios seres humanos. Dessa forma, os extremos da racionalidade científica e ambiente desnaturalizado nos levam a comportamentos que se ancoram em uma espécie de niilismo, como se fosse possível existir inteiramente fora das leis da natureza (p. 236).

Porém, frente ao fato de que a tecnociência não pode ser exclusivamente considerada como modus operandi - que se expressa na forma de um conjunto maior que a somatória da ciência e técnica -, mas sim um modus vivendi, uma vez que se faz presente em praticamente todas as relações sociais, são as seguintes as questões que se colocam: o laboratório de ensino onde se realizam as práticas experimentais não poderia ser identificado como um lócus de experiência formativa? Que conceito de experiência poderia ser utilizado para além de sua dimensão instrumentalizada? De que modo os estudantes compreendem as características definidoras de tal conceito? Assim, tem-se, como principal objetivo neste artigo, argumentar que o laboratório 
pode ser caracterizado como um local de desenvolvimento de tais experiências formativas, à luz da Teoria Crítica da sociedade. Para tanto, em um primeiro momento faz-se necessário apresentar as bases epistemológicas do que aqui se compreende como experiência formativa, partindo das linhas teóricas correntes sobre o tema, com ênfase nos escritos de Theodor Adorno e Walter Benjamin.

\section{O CONCEITO DE EXPERIÊNCIA E SUAS IMPLICAC̣ÕES FORMATIVAS}

No texto intitulado "Teoria da semiformação", Theodor Adorno (19031969) destaca, entre outros aspectos, a forma como o conceito de formação cultural (Bildung) se disseminou na ascensão do modo de produção capitalista:

A formação devia ser aquela que dissesse respeito - de uma maneira pura como seu próprio espírito - ao indivíduo livre e radicado em sua própria consciência, ainda que não tivesse deixado de atuar na sociedade e sublimasse seus impulsos. A formação era tida como condição implícita a uma sociedade autônoma: quanto mais lúcido o singular, mais lúcido o todo. Contraditoriamente, no entanto, sua relação com uma práxis ulterior apresentou-se como uma degradação a algo heterônomo, como percepção de vantagens de uma irresolvida bellum omnium contra omnes (ADORNO, 2010, p. 13).

Quanto mais lúcido fosse o indivíduo, mais lúcida seria a própria sociedade, contribuindo para evitar a guerra de todos contra todos. Ou seja, mesmo que o indivíduo tivesse que, psicanaliticamente, sublimar seus impulsos, essa não seria uma prerrogativa exclusivamente sua, pois todos teriam de proceder da mesma forma. Assim, a sublimação pulsional, ilustrada no respeito às normas dos contratos sociais vigentes e, portanto, na reflexão sobre as consequências do próprio comportamento em relação a outro indivíduo, se transformaria na condição de exercício da própria liberdade. Em termos filosóficos, essa pretensão de autonomia foi enfatizada por Kant (1724-1804), sobretudo na sua assertiva de que o indivíduo emancipado, que ousaria fazer uso do próprio esclarecimento e, desse modo, se insurgiria contra as formas de tutelagem impostas pela igreja, seria o indivíduo pertencente ao denominado mundo letrado (KANT, 2005).

É nesse contexto que a formação cultural pode ser identificada como experiência formativa crucial para o desenvolvimento das identidades coletiva e individual. Mas, para que tal experiência se desenvolvesse, seria fundamental que seus dois eixos centrais se afirmassem no decorrer do processo formativo: a continuidade e a temporalidade. A continuidade refere-se à necessidade de que os conteúdos culturais permaneçam presentes, ainda que modificados, no decorrer desse processo. Desse modo, torna-se decisivo o desenvolvimento da capacidade de o indivíduo estabelecer relações cada vez mais complexas entre os conteúdos das mais variadas áreas do conhecimento. As informações recebidas precisam ser relacionadas entre si para que possam ser concebidas, e não apenas justapostas sem a reflexão que permite fazer com que as ligações entre estas se transformem em conteúdos ressignificados.

A outra característica determinante da experiência formativa, ou seja, a temporalidade, diz respeito à necessidade de se considerarem os vínculos temporais entre os produtos simbólicos e suas respectivas assimilações. Procuram-se evitar 
procedimentos que invalidem a historicidade imanente presente nesses produtos culturais. Pois, considerar o modo como as mediações históricas se objetivam na tessitura desses produtos implica a possibilidade de que alternativas de identidade, que ainda não se concretizaram, sejam revitalizadas em tempos vindouros. Walter Benjamin (1892-1940) expressou poeticamente essa possibilidade quando observou a relevância de se poder ler a história a "contrapelo", dado que o "passado traz consigo um índice misterioso, que impele à redenção. Pois não somos tocados por um sopro de ar que foi respirado antes? Não existem, nas vozes que escutamos, ecos de vozes que emudeceram?” (BENJAMIN, 1985, p. 223). Ouvir essas vozes também significa que elas podem ser materializadas em novas relações sociais, de tal maneira que o indivíduo que as considera se religue não somente com seu passado, como também com o da sua própria coletividade. Contudo, a religação não o aprisiona às relações passadas, mas sim, ao considerá-las, ele se projeta para tempos de experiências futuras, justamente porque a história do particular e do todo foi também lida a "contrapelo". Para que esse movimento ocorra, a memória de tais vínculos precisa estar sempre presente. De acordo com Benjamin;

\footnotetext{
Onde há experiência no sentido estrito do termo, entram em conjunção, na memória, certos conteúdos do passado individual com outros do passado coletivo. Os cultos, com seus cerimoniais, suas festas (...) produziam reiteradamente a fusão desses dois elementos na memória. Provocavam a rememoração em determinados momentos e davam-lhe o pretexto de se reproduzir durante toda a vida. As recordações voluntárias e involuntárias perdem, assim, sua exclusividade recíproca (BENJAMIN, 1991, p. 107).
}

Para Benjamin, justamente essa coligação possibilitada pela memória, entre os elementos do passado individual e coletivo durante a realização dos cultos, cerimoniais e protocolos, fomentava as bases da experiência. Assim, destacase também sua dimensão formativa, pois o indivíduo seria capaz de identificar a produção histórica de sua própria identidade com o coletivo, a ponto de as recordações voluntárias (conscientes) e as involuntárias (inconscientes) perderem sua exclusividade recíproca. Ou seja, tais recordações se relacionariam de tal modo que uma se fundamentaria na outra, principalmente porque a memória recuperaria as mediações históricas presentes na relação de continuidade e temporalidade dos conteúdos do passado, tanto individual quanto coletivo. Dito de outra maneira, a vivência (Erlebnis) seria metamorfoseada em experiência (Erfahrung): os elementos e informações pontuais cotidianamente vivenciados seriam ligados de tal maneira entre si que promoveriam experiências formativas, a ponto, portanto, do conhecimento ser efetivamente apreendido. A produção da experiência (e da memória involuntária) não se baliza na eliminação da dimensão da vivência (e da memória voluntária), mas sim no processo social que conserva e supera os eventos do cotidiano que convergem na chamada memória voluntária. O elemento de duração da experiência precisa ser associado à consciência do presente que depreende a relevância do passado na sua composição, bem como intui a sua importância na constituição do futuro.

Apesar de certas diferenças em relação ao conceito de experiência ${ }^{2}$, Theodor Adorno e Walter Benjamin destacaram a necessidade de que as informações obtidas em quaisquer processos educacionais não permanecessem isoladas entre si, 
ou seja, que fossem continuamente relacionadas, promovendo a criação de novos conceitos. Entretanto, a industrialização crescente dos produtos simbólicos tem gerado danos consideráveis na formação cultural e nas experiências formativas. Em tempos da consolidação da denominada indústria cultural, a formação se converteu em semiformação, de tal maneira que a experiência foi substituída por um:

(...) estado formativo pontual, desconectado, intercambiável e efêmero, e que se sabe que ficará borrado no próximo instante por outras informações. Em lugar do temp durée, conexão de um viver em si relativamente uníssono que desemboca no julgamento, coloca-se um "É assim" sem julgamento, algo parecido à fala dos viajantes que, do trem, dão nomes a todos os lugares pelos quais passam como um raio, a fábrica de rodas ou do cimento, o novo quartel, sempre prontos a dar respostas inconsequentes a qualquer pergunta. A semiformação é uma fraqueza em relação ao tempo, à memória, única mediação capaz de fazer na consciência aquela síntese da experiência que caracterizou a formação cultural em outros tempos (ADORNO, 2010, p. 33).

Em termos benjaminianos, a semiformação poderia ser caracterizada como a hegemonia das vivências que não se convertem em experiências. O que prevalece em relação à aquisição de conhecimentos é justamente seu estado formativo pontual, fragmentado, intercambiável e efêmero. O tempo de duração da informação absorvida se reduz a instantes que se volatilizam na mesma velocidade na qual outras informações surgem e substituem as anteriores. Por essa razão, Adorno definiu a semiformação como uma fraqueza em relação ao tempo e à memória. $\mathrm{O}$ indivíduo semiformado muitas vezes tenta justificar a falta do aprofundamento de sua reflexão em determinados temas, justamente por não ter o tempo necessário para poder se concentrar nas informações recebidas. Porém, essa justificativa do indivíduo semiformado não pode ser associada exclusivamente às suas idiossincrasias, pois se faz necessário compreender o modo como o espírito objetivo de um tempo ou de uma determinada cultura determina a atual forma como a capacidade de concentração é pulverizada (ZUIN, ZUIN, 2016).

Diante da torrente cada vez maior de estímulos viciantes, majoritariamente audiovisuais, recrudesce o fenômeno da distração concentrada, a atual forma de revitalização da semiformação, pois "o meio de concentração se torna o próprio meio de decomposição” (TÜRCKE, 2010, p. 266). Logo, a capacidade de concentração é como que pulverizada, uma vez que ela não se fixa nas informações no tempo necessário para que haja a produção da reflexão conceitual. Justamente a alternância contínua e ininterrupta dos links faz com que os dados informacionais sejam qualitativamente transformados, ou não, em conceitos, seja em ambientes presenciais ou virtuais (ou na ausência aparente de limites entre estes). Assim, dificilmente as informações obtidas pelo acesso aos mais variados meios são criticamente refletidas, na medida em que o tempo de duração do contato com tais informações se arrefece cada vez mais. É como se os conteúdos e os meios de acesso a esses disputassem titanicamente entre si a atenção daquele que consome suas imagens, ferramentas e sons, nem que seja por breves instantes. Ou seja, o acesso a uma miríade de links materiais e imateriais porta consigo o seguinte contraste: o contato com um número infinito de dados não significa necessariamente a ampliação da capacidade de se 
elaborar representações e conceitos, haja vista que as ligações vivenciadas, os links, permanecem em seu estado informativo pontual e efêmero.

O fenômeno da distração concentrada se dissemina de forma cada vez mais acelerada, pois prolifera nos mais variados níveis escolares. Há “autores" que simplesmente copiam as informações e as colam sem relacioná-las entre si em um novo texto, sendo que essa prática pode produzir situações de plágio que, em várias ocasiões, nem são reconhecidas como tal por aqueles que procedem dessa forma. Muitas vezes, a bricolagem de textos é aprovada pelo olhar complacente do professor, o qual, ao agir dessa forma, também referenda a atualização do que Adorno denominou como semiformação, ou seja, como experiência formativa danificada (ZUIN, 2011). Os roteiros experimentais, a própria prática disponibilizada como vídeos editados com os mais variados propósitos (e registradas em off, ou não, por estudantes e /ou outros), os relatórios dos experimentos já com todas as respostas e, em grande maioria, idênticos aos executados nas instituições de ensino superior, por exemplo, podem ser acessados em sites especializados a qualquer momento, inclusive durante o próprio desenvolvimento do experimento, em que, muitas vezes, o relato se resume a um formulário a ser entregue ao final da aula. E se essa prática da bricolagem, tão afeita à chamada distração concentrada, viceja cada vez mais atualmente, as seguintes questões se colocam: de que maneira os estudantes elaboram suas respectivas experiências em laboratório? Essas mesmas experiências poderiam ser identificadas como formativas (Erfahrung) de acordo com Adorno e Benjamin? A seguir, serão elaboradas considerações sobre os teores de tais questionamentos.

\section{A PRÁTICA LABORATORIAL DE QUÍMICA COMO EXPERIÊNCIA FORMATIVA}

De maneira geral, pode-se verificar a tendência de se considerar historicamente a Química como uma ciência experimental em sua essência, cujos ensaios laboratoriais muitas vezes parecem ser separados dos determinantes socioculturais que os produzem ${ }^{3}$. Com efeito, tais práticas adquiriram tamanho vulto que parece prevalecer a máxima de que "ver é compreender" (GALIAZZI; GONÇALVES, 2004), em uma revitalização laboratorial do conhecido dito de São Tomé concernente à necessidade imperiosa do ver para poder crer. De acordo com essa premissa, os trabalhos desenvolvidos nos laboratórios são considerados uma espécie de absolutos, filosoficamente falando. Ou seja, eles seriam algo em si e por si, regidos por uma lógica peculiar e sem relação direta com as estruturas sociais que os produziram. Da forma como praticados em laboratórios de Pesquisa, Desenvolvimento, Inovação e Aplicação em Ciência e Tecnologia (PDI\&A em C\&T), e ressignificados (ou não) nos espaços reservados para o ensino, a definição dos experimentos, métodos e modelos teóricos ocorre no campo agonístico, no qual determinados enunciados e processos são legitimados em detrimento de outros. A síntese dessas noções possibilita a reflexão sobre o fato de que ela não é produto de atitudes consensuais desprovidas de conflitos, pois:

A atividade científica (e seu ensino) não trata da "natureza", ela é uma luta renhida para construir a realidade. O laboratório é o local de trabalho e o conjunto das forças produtivas 
que torna essa construção possível. Cada vez que um enunciado é estabilizado, ele é reintroduzido no laboratório (sob a forma de máquina, inscritor, de saber, de rotina, de pré-requisitos, de dedução, de programa etc.), e aí é utilizado para aumentar a diferença entre diversos enunciados (LATOUR; WOOLGAR, 1997, p. 278).

A vida nos laboratórios também reflete as tensões existentes no modo de produção vigente, que determinam quais serão os enunciados constitutivos da realidade e, portanto, legitimados para serem ensinados dentro e fora da Química (ZUIN, 2011). Diante desse quadro, o que parece verdadeiramente importar é a realização de uma prática que se utiliza da teoria apenas para poder corroborar seus resultados. Quando o ver significa compreender, em uma típica relação de causa e efeito, em um sentido benjaminiano e adorniano, a própria prática de pesquisa se torna instrumentalizada para se evitar sobremaneira quaisquer tipos de confrontos com os pressupostos teóricos com os quais se relaciona. Justamente por se tornar reificada a tal ponto, a prática parece bastar-se a si própria, como se fosse completamente independente da teoria que a fundamentou. E exatamente neste momento que as informações, derivadas do processo de instrumentalização da prática laboratorial, se caracterizam como efêmeras e pontuais, cuja fragmentação reafirma o sentido de semiformação como foi anteriormente exposto. De fato, tornou-se discurso comum o dos professores que pregam o credo da objetividade científica, que deve ser caracterizada como absolutamente neutra, linear, acumulativa e, portanto, destituída por completo de quaisquer juízos de valores (GONÇALVES; MARQUES, 2012), mas essas crenças necessitam ser recolocadas atualmente.

Por exemplo, nos últimos anos, vários vídeos voltados para os experimentos de Química têm sido postados em plataformas diversas, principalmente no YouTube (SILVA et al., 2016). ${ }^{4}$ Os experimentos partilhados na Internet, até mesmo por professores, evidenciam a atualidade dos conceitos de formação e, principalmente, semiformação. Muitas vezes, a essência (experimento didático) é sombreada pelo protagonismo dado, por exemplo, ao "susto" dos estudantes, decorrente da explosão de um balão preenchido com hidrogênio. A novidade partilhada e renovada em tempos de Internet, para além do experimento, é a ridicularização dos indivíduos, propositalmente programada e capturada pelo proponente do experimento ou por aquele que o compartilha em outras redes. De acordo com Türcke (2010), percebe-se, na sociedade contemporânea, altamente dependente de meios tecnológicos e das "sensações", que a crítica só se efetiva quando articulada aos processos violentos que se atualizam cotidianamente, também nas telas dos aparatos eletrônicos. Outra novidade neste experimento partilhado nas redes é a ausência da possibilidade de ser removido definitivamente da memória eletrônica e, portanto, do mundo material mais imediato.

De fato, não é possível apartar a prática laboratorial que se pauta na produção de resultados de curta duração da sociedade na qual esse tipo de prática se insere. Pois é na atual sociedade que as atividades laboratoriais tendem a ser identificadas como práticas que confirmam seus pressupostos teóricos, sem questionamentos, de tal forma que os pressupostos que não as atestem devem ser descartados. A informação gerada por esse processo revela sua pretensão de autossuficiência, como se pudesse ser absolutamente afastada dos interesses daqueles que as elaboraram. Contudo, a 
prática assim concebida se torna objeto de contestação, tal como pode ser observado na literatura (HODSON, 1990; LUNETTA, HOFSTEIN, CLOUGH, 2007; SJOSTROM, EILKS, ZUIN, 2016), em que se faz necessário refletir radicalmente sobre a concepção da maior parte dos professores em relação ao significado do trabalho experimental. Evidentemente, tal redefinição implica a crítica do modo como as conjecturas teóricas são, em muitas ocasiões, completamente desconsideradas, ou então utilizadas para meramente confirmar, de antemão, a "veracidade" dos resultados que ainda serão obtidos. De acordo com esse procedimento,

\begin{abstract}
(...) a experiência surge, quase sempre, como algo episódico, ligada a uma visão heroica do cientista; ignora os contextos sociais, tecnológicos e culturais da construção e produção científica, que o professor tem de conhecer e não desconsiderar, deixando à margem das suas aulas. Caso contrário, a experiência científica escolar toma o sentido do fazer, sem saber por que e para quê, colocando a ciência em uma lógica que está fora da própria história do pensamento das ideias, desvalorizando o sentido da própria luta por ideias mais verdadeiras, isto é, mais explicativas para os fenômenos naturais (PRAIA; CACHAPUZ; GIL-PÉREZ, 2002).
\end{abstract}

O risco da imagem do cientista como herói prevalecer no imaginário social pode suscitar a constatação de que todos os problemas e dilemas produzidos nos laboratórios podem ser exclusivamente solucionados mediante a intervenção arrojada do cientista. Contudo, esse tipo de personalização pode reforçar a ideologia de que os problemas de ordem social sejam sanados unicamente por meio de decisões idiossincráticas. A verdade de que as decisões subjetivas conservam sua relevância na identificação das variáveis e dos resultados pertinentes à resolução de certos problemas não pode ser utilizada no intuito de se desconsiderar a importância de se compreenderem os mecanismos sociais que determinam o modo como os próprios experimentos científicos e seu ensino e divulgação são majoritariamente realizados.

Até mesmo a forma como as hipóteses de determinados experimentos são elaboradas é prenhe do caldo cultural hegemônico de uma determinada época. Assim, para Horkheimer, a relação que se estabelece entre hipótese e fato "não se realiza na cabeça dos cientistas, mas na indústria. A regra que a nitroglicerina possui grande força explosiva constitui um saber acumulado que é aplicado efetivamente aos fatos nas fábricas e nos grandes trustes" (HORKHEIMER, 1991, p. 36). Ou seja, a relação que se estabelece entre hipóteses e fatos por qualquer pesquisador não surge de forma separada da sociedade a que esse cientista pertence, sobretudo pelo fato de que a intenção, por exemplo, de se fabricar a nitroglicerina não pode ser identificada "apenas" como um propósito técnico regido pelo controle de determinadas variáveis. Sabe-se, de antemão, que seus resultados literalmente impactarão na vida das pessoas porque o controle da produção será feito pelos grandes trustes empresariais. É interessante observar que o próprio Horkheimer critica a figura do especialista que, como cientista, observa a realidade como algo exterior e, como cidadão, mostra seu interesse pela realidade enquanto ensaísta político ou então como participante de associações beneficentes. Ao proceder dessa forma, reforça-se a dicotomia indivíduo-sociedade. Consequentemente, a principal motivação do pensamento crítico refere-se à tentativa de se "superar realmente 
a tensão, de eliminar a oposição entre consciência dos objetivos, espontaneidade e racionalidade inerentes ao indivíduo, de um lado e as relações do processo de trabalho, básicas para a sociedade, de outro lado" (HORKHEIMER, 1991, p.46).

Evidentemente, a importância de se considerar a hipótese de trabalho de qualquer experimento científico como uma elaboração de caráter social não anula nem a relevância do sujeito, no caso o cientista e/ou professor, nem a necessidade de sua própria existência para o desenvolvimento das etapas dos experimentos laboratoriais. A intenção de se identificar a hipótese como uma elaboração conceitual individual e coletiva se fundamenta na necessidade de se relacionar o processo de verificação dos fatos, cujos resultados comprovarão ou não as premissas hipotéticas iniciais, com as características socioculturais presentes na forma e no conteúdo das próprias hipóteses. Exatamente a consideração das mediações socioculturais presentes na tessitura das hipóteses recoloca a própria teoria que as fundamentaram em um outro patamar, pois, se "a hipótese intervém ativamente nas explicações que os resultados da experiência sugerem, a teoria tem um papel primordial na avaliação dos resultados obtidos" (PRAIA, CACHAPUZ, GIL-PEREZ, 2002, p. 257). Dessa forma, para Adorno;

O conteúdo de verdade do discurso sobre a unidade de teoria e prática liga-se a condições históricas. Em pontos nodais do desenvolvimento, de ruptura qualitativa, podem reflexão e ação detonar-se mutuamente, mas nem mesmo então são ambas a mesma coisa (ADORNO, 1995, p. 210).

A constatação de que reflexão e ação, bem como teoria e prática são conflituosamente interdependentes, uma vez que suas identidades se conservam transformadas no movimento dialógico que estabelecem entre si, possibilita que a própria relação entre forma e conteúdo das hipóteses seja qualitativamente problematizada. Esse movimento faz com que a hipótese deixe de ser uma camisa de força cujas premissas devem ser comprovadas a qualquer preço. Desse modo, a própria experiência científica passa a ser questionada pela concepção teórica que fundamenta suas bases epistemológicas. Ao refletir sobre a Educação Química pautada no desenvolvimento de atividades que estimulem uma relação dialógica entre teoria e prática, há alguns caminhos discutidos na literatura que podem contribuir para uma práxis mais adequada aos pressupostos colocados neste artigo, a saber: apresentação de situações-problema relacionadas a temas tecnocientíficos que despertem interesse e proporcionem uma concepção preliminar da tarefa (tendo em conta as ideias, visões de mundo, as destrezas e atitudes dos estudantes); proposição de estudos qualitativos das situações e decisões para delimitar problemas sociocientíficos (ocasião para que comecem a explicitar funcionalmente suas ideais e começar a conceber um plano para o seu enfrentamento); orientação do tratamento dos problemas apresentados, que contemple a emissão de hipóteses, a elaboração de estratégias para a contestação dessas e a análise de resultados, considerando as previsões, comparando-os com os obtidos por outros grupos de estudantes e pela comunidade científica e apresentação da condução reiterada dos novos conhecimentos em uma variedade de situações, para fazer possível o seu aprofundamento, dirigindo todo 
o tratamento para mostrar o caráter de corpo coerente que tem toda a ciência, favorecendo as atividades de síntese, a elaboração de produtos e a concepção de novos problemas (GIL-PEREZ et al., 1999; MASSI, GIORDAN, 2014).

De acordo com essa abordagem, as hipóteses podem ser constituídas tendo-se como premissa fundamental a relação estabelecida entre os objetos de análise e as condições socioculturais que as produziram. Assim, os temas científicos selecionados, muitas vezes controversos, podem ter a função de estimular as relações entre os conceitos e as práticas laboratoriais feitas pelos agentes educacionais, até mesmo na formação de formadores (GONÇALVES, MARQUES, 2016). Por exemplo, pode-se propor a abordagem de uma questão sociocientífica controversa como a produção, em larga escala, de biodiesel no Brasil, um projeto defendido pelo governo federal. Os conceitos e procedimentos químicos como a preparação da matéria-prima, a reação de transesterificação, a separação de fases, recuperação e desidratação do álcool, a destilação da glicerina e purificação do biodiesel podem ser discutidos e associados aos aspectos sociais e ambientais, como a potencial crise alimentar no mundo. Nesse caso, a síntese de biodiesel em laboratório ocorre de forma problematizada e crítica, por meio da qual se pode solicitar uma pesquisa bibliográfica atualizada sobre o assunto (leitura de artigos científicos, de jornais e revistas, de sites da internet); a proposição de roteiros para a obtenção do combustível; o questionamento sobre qual matéria-prima possibilitaria o maior rendimento reacional (grãos de soja, sementes de girassol, grãos de amendoim etc.); os cuidados relativos ao manejo dos reagentes, dentre outros. Como se pode notar, os estudantes são convidados a participar ativamente na construção de seu saber - quer conceitual, procedimental ou atitudinal - que só ocorre em um ambiente em que o professor caminha, intencionalmente, a par das dificuldades e potenciais do estudante, situando-as no contexto sócio-histórico contemporâneo.

Embora não tenham utilizado a expressão camisa de força para se referir a um tipo de hipótese que como que engessa, por assim dizer, o próprio movimento do experimento científico, Praia et al. (2002) asseveraram a possibilidade de elaboração de uma concepção de experiência científica que se contrapõe a esse tipo de imobilização, haja vista que: "A experiência enquadra-se em um método que comporta uma diversidade de caminhos, ajustando-se ao contexto e à própria situação investigativa. Os seus resultados são lidos como elementos (possíveis) de construção de modelos interpretativos do mundo e não cópias (e muito menos fiéis) do real" (2002, p. 257).

São muitas as veredas que compõem a diversidade de caminhos, conforme se desenvolvam as etapas dos experimentos laboratoriais. Mas o encontro de tais veredas pode ser feito por meio do convite ao diálogo que o professor de Química propõe aos seus estudantes. Ou seja, os estudantes poderiam ser estimulados pelo professor a refletir e opinar a respeito da elaboração tanto das hipóteses, quanto das etapas que constituirão os experimentos. Segundo essa perspectiva de análise, há a necessidade de que ocorram duas condições fundamentais. Na primeira, o professor tem a consciência de que sua aparente superioridade é, antes de tudo, contingencial, o que implicaria a realização da autocrítica referente ao conceito de autoridade pedagógica. Ao refletir sobre as caraterísticas de tal conceito, Horkheimer pontua que “(...) a autoridade valeria como uma relação em que alguém se submeteria 
racionalmente a outrem, pois, em virtude de uma superioridade factual, encerraria em si a tendência para superar a si própria" (HORKHEIMER, 1983, p.102). Dessa maneira, recomenda-se que o professor de Química, sobretudo no nível universitário ${ }^{5}$, perceba que todas as vezes nas quais os estudantes participam da aula experimental com questionamentos sobre as características das práticas, há a participação também do educador; pois, justamente as ideias do professor se conservam, transformadas nas reflexões que os estudantes se sentem instigados a publicamente compartilhar, primeiramente nesse coletivo. Em outras palavras, os estudantes abandonam sua posição de indivíduos passivos também devido à autocrítica feita pelo professor, que não mais se considera o dono da verdade, das hipóteses que precisam ser confirmadas de maneira irredutível.

A segunda condição é de que os estudantes se sintam motivados a relacionar, sócio-historicamente, os conteúdos apresentados, tal como pontuado por Adorno e Benjamin, ao situarem os experimentos laboratoriais em relação ao tempo e ao espaço nos quais foram desenhados. Quando percebem que tais experimentos não são absolutos, ou seja, não surgiram do nada, mas são resultados de construções e experiências humanas, os próprios estudantes tendem a reconhecer que, se as hipóteses, etapas e resultados dos experimentos são produtos de tais intervenções, eles próprios podem também intervir neste processo. É dessa forma que o significado da experiência formativa é resgatado, principalmente pelo fato de que seus dois elementos constituidores, a continuidade e a temporalidade dos conteúdos culturais são reforçados pelo modo como os alunos concebem e participam da construção das etapas presentes no decorrer da realização dos experimentos laboratoriais. De acordo com Goergen (2014):

\footnotetext{
O pensamento puramente operacional concentra-se nos experimentos e abole a experiência. Experiência significa ter a percepção dos problemas e fazer o trabalho do pensamento, desvelando as formas históricas da razão, seus fluxos, remansos e refluxos. Fazer a experiência do pensar é, pois, suspeitar das locuções do real, da lógica do pensamento puramente instrumental que hoje nos enquadra e condiciona. É arriscar-se a admitir que a objetividade das provas não deve ser o limite do humano, nem seu descanso final. É o trabalho do espírito que ultrapassa a velocidade da reprodução técnica. (p. 572)
}

A reprodução irrefletida, também produto da velocidade e urgência de nosso tempo, necessita ser freada, levando o pensamento adiante dos acontecimentos. Portanto, ir a "contrapelo" e na contramão da lógica tecnocientífica instrumentalizada também nos laboratórios de ensino, para que os bens culturais sejam compreendidos para além de sua pura aplicação e validação na esfera da produção e do mercado. A Educação Química, pautada em uma abordagem investigativa em laboratório, exige repensar tanto o papel da prática quanto dos agentes educacionais e suas instituições. As problemáticas abordadas requerem que se rompa com as tradicionais dicotomias entre saberes e valores, o teórico e o prático, campos tecnocientíficos e os humanísticos, ambientes físicos e virtuais que são condições necessárias para uma renovação educativa orientada para a revitalização do conceito de experiência formativa, lugares e formas de apropriação dos conhecimentos em nosso tempo. 


\section{CONSIDERACִ̃̃ES FINAIS}

Identificar o laboratório como espaço para experiências formativas à luz da Teoria Crítica implica, primeiramente, a reconfiguração da relação estabelecida entre teoria e prática associadas à continuidade e temporalidade que se desenvolve neste lócus. É preciso que os agentes educacionais - professores, estudantes, técnicos e demais envolvidos - considerem a importância de que a realização das etapas de todo experimento fundamenta-se, na realidade, em pressupostos epistemológicos de uma determinada teoria. E que tal teoria é produto das determinações socioculturais, de modo que tanto a prática quanto a teoria precisam ser criticamente relacionadas pelos agentes educacionais. Se houver tal relação dialógica, serão produzidas reais condições para que os experimentos científicos se tornem experiências formativas, no sentido que foi destacado anteriormente com base nos escritos de Theodor W. Adorno e Walter Benjamin. O próprio desenvolvimento das práticas laboratoriais, em muitas ocasiões, impinge a necessidade de que tanto as hipóteses quantos os pressupostos teóricos sejam modificados, uma vez que professores e estudantes, em um trabalho em conjunto, refletem e dialogam sobre a necessidade de tais mudanças. Evidentemente, para que este tipo de intervenção ocorra, fazse necessário que o professor proceda no sentido de cada vez mais permitir que os estudantes possam interceder nos rumos dos diversos caminhos surgidos no transcorrer do desenvolvimento do trabalho em laboratório. Já os estudantes, motivados a abandonar a passividade que trava o processo educacional/formativo, tornam-se ativamente responsáveis pela condução e pelos desdobramentos dos experimentos científicos didáticos. Tal como observado, é preciso fazer com que os estudantes reflitam sobre o fato de que as práticas são produções humanas, e não algo completamente isolado das conjecturas de uma sociedade historicamente localizada, cujas relações entre os indivíduos moldam tanto as características de tais práticas, quanto às dos constructos teóricos.

Evidentemente, o desenvolvimento de experiências formativas não é tão comum a ponto de ocorrer simplesmente porque os agentes educacionais desejam que se torne uma realidade indefectível. São muitos os obstáculos de ordem objetiva e subjetiva que travam a possibilidade de que tais experiências se transformem em uma realidade efetivamente presente na maioria dos laboratórios, como as precárias condições de trabalho dos professores, a insuficiência de materiais e instrumentos, as resistências de diversas naturezas às mudanças em função dos recursos (número de estudantes, aulas práticas previstas etc.). Ao lado de tais obstáculos, nota-se o recrudescimento da denominada distração concentrada, tal como foi anteriormente destacado por Türcke (2010). Esse fenômeno decorre de uma cultura que tende a fragmentar a produção do raciocínio, uma vez que as mais variadas informações obtidas por meio do acesso aos linkes virtuais dificilmente são relacionadas entre si, a ponto de poder proporcionar o salto qualitativo referente à produção dos conceitos ressignificados.

Contudo, mesmo diante de tais barreiras, as instituições de ensino ainda conservam em si a possibilidade de realização de sua autocrítica, de tal modo que cada vez mais seja estimulada a criação de espaços dialógicos entre os agentes educacionais. Certamente, o laboratório pode ser identificado como um desses locais, sobretudo 
quando os questionamentos conjuntamente produzidos pelos professores, estudantes e técnicos são elaborados de modo a relacionar criticamente as práticas com as teorias que as fundamentam, de maneira a dar lugar e tempo para experiências, por meio da continuidade e da temporalidade. Essas possibilitam conhecer os problemas e as suas possíveis formas de enfrentamento, descortinando racionalidades e atos instrumentalizados de maneira sócio-historicamente situada, em busca da formação experienciada, no sentido proposto por Theodor Adorno e Walter Benjamin.

\section{NOTA}

${ }^{1}$ Esta pesquisa foi financiada pelo Conselho Nacional de Desenvolvimento Científico e Tecnológico (CNPq; Proc. n. 304811/2013-0 e 311000/2014-2) e Fundação de Amparo à Pesquisa do Estado de São Paulo (FAPESP; Proc. n. 15/24736-1).

${ }^{2}$ Uma dessas diferenças refere-se à ênfase dada por Benjamin à relação entre experiência e memória involutária, ou seja, à dimensão inconsciente da própria experiência.

${ }^{3}$ Como descrito na literatura, cabe conhecer como a comunidade da Química estabelece e compreende o papel dos experimentos no Ensino e/ou Educação Química, a saber: a relação existente entre atividade experimental e motivação; a natureza epistemológica da experimentação; a importância de um contexto dialógico para a aprendizagem; as condições materiais para o desenvolvimento de atividades experimentais; as características dos conteúdos ensinados por meio dos experimentos, dentre outros aspectos (GONÇALVES; MARQUES, 2006; 2012; ZUIN, 2011).

${ }^{4}$ Em uma busca simples realizada no YouTube do termo "experimentos didáticos em química", um número superior a 310.000 vídeos pôde ser encontrado (03/2017).

${ }^{5}$ É importante observar que há pesquisas, de outras matrizes teóricas, sobre a presença dessa relação dialógica entre estudantes e professores de Química do ensino médio, tal como pode ser observado, por exemplo, no livro organizado por Santos e Greca (2006).

\section{REFERÊNCIAS}

ADORNO, Theodor. W. Palavras e sinais: modelos críticos 2. Petrópolis: Vozes, 1995.

ADORNO, Theodor. W. Teoria da semiformação. Trad. Newton Ramos-de-Oliveira. In: PUCCI, Bruno. ZUIN, Antônio. A. S.; LASTÓRIA, Luiz A.C.B. (Orgs.) Teoria crítica e inconformismo: novas perspectivas de pesquisa. Campinas: Autores Associados, 2010.

BACON, Francis. Novum Organum ou verdadeiras indicações acerca da interpretação da natureza/Nova Atlântida, coleção: Os Pensadores. Trad. José Aluysio Reis de Andrade. São Paulo: Abril Cultural, 1973. (Coleção Pensadores)

BENJAMIN, Walter. Magia e técnica, arte e política. Trad. Sergio Paulo Rouanet. São Paulo: Brasiliense, 1985.

BENJAMIN, Walter. Charles Baudelaire: um lírico no auge do capitalismo. Trad. Jose Carlos Martins Barbosa e Hemerson Alves Baptista. São Paulo: Brasiliense, 1991.

CACHAPUZ, A.; GIL-PEREZ, D.; CARVAlhO, A. M. P.; PRAIA, J.; VILCHES, A. (Org.) A necessária renovação do ensino das Ciências. São Paulo: Cortez, 2005.

GALIAZZI, M.C.; GONÇALVES, F.P. A natureza pedagógica da experimentação: uma pesquisa na 
licenciatura em química. Química. Nova, v. 27, n. 2, 2004.

GIL-PEREZ, D. et al. . Tiene sentido seguir distinguiendo entre aprendizaje de conceptos, resolución de problemas de lápiz y papel e realización de prácticas de laboratorio. Enseñanza de las Ciencias, v.17, n. 2, p. 311-320, 1999.

GONÇALVES, F. P.; MARQUES, C. A. Contribuições pedagógicas e epistemológicas em textos de experimentação no ensino de química. Investigações em Ensino de Ciências, v. 11, p. 1, 2006.

GONÇALVES, F.P.; MARQUES, C.A. Problematización de las actividades experimentales en la formación y la práctica docente de los formadores de profesores de Química. Enseñanza de las Ciencias, v. 31, p. 67-86, 2013.

GONÇALVES, F. P.; MARQUES, C.A. A Experimentação na Docência de Formadores da Área de Ensino de Química. Química Nova na Escola, v. 38, p. 84-98, 2016.

GOERGEN, P. Tecnociência, pensamento e formação na educação superior. Avaliação, v. 19, n. 3, p. 561-584, 2014.

HODSON, D. A critical look at pratical work in school Science. School Science Review, v. 70, n. 256. p. 33-40, 1990.

GRECA, Ilena Maria; SANTOS, Flávia Maria Teixeira (Org). A pesquisa de ensino de ciências no Brasil e suas metodologias. Ijuí: Editora Unijuí, 2006.

HORKHEIMER, Max. Autoridade e família. Lisboa: editora Apáginastantas, 1983.

HORKHEIMER, Max. Teoria tradicional e teoria crítica: In: HORKHEIMER, Max; ADORNO, HORKHEIMER, Max. Teoria tradicional e teoria crítica: In: HORKHEIMER, Max; ADORNO, Theodor W. Textos escolhidos. Trad. Edgard Afonso Malagodi e Ronaldo Pereira Cunha. São Paulo: Nova cultural, 1991. (Coleção Os Pensadores).

KANT, Immanuel. Resposta à pergunta: que é esclarecimento. In: KANT, Immanuel. Textos seletos. Trad. Floriano de Sousa Fernandes. Petrópolis: Vozes, 2005.

LUNETTA, Vincent N., HOFSTEIN, Avi; CLOUGH Michael. Learning and teaching in the school science laboratory: an analysis of research, theory, and practice. In: LEDERMAN, Norman G.; ABEL, Sandra K. (Eds.). Handbook of research on science education. Mahwah: Lawrence Erlbaum, 2007. p. 393-441.

MASSI, L.; GIORDAN, M. Introdução à pesquisa com sequências didáticas na formação continuada online de professores de ciências. Revista Ensaio, v. 16, n. 3, p. 75-93, 2014.

PRAIA, J.; CACHAPUZ, A.; GIL-PÉREZ, D. A hipótese e a experiência científica em educação em ciência: contributos para uma reorientação epistemológica. Ciência \& Educação, v. 8, n. 2, p. 253-262, 2002.

SANTOS, Laymert. G. Politizar as novas tecnologias: o impacto sócio-técnico da informação digital e genética. São Paulo: Ed. 34, 2003.

SCHANK, Patricia, KRAJCIK, Joseph, YUNKER, Molly. Can nanoscience be a catalyst for educational reform? In: ALLHOF, Fritz; LIN, Patrick; MOOR, James; SJOSTROM, J.; EILKS, I.; ZUIN, V.G. Towards eco-reflexive science education: a critical reflection about educational implications of green chemistry. Science \& Education, v. 25, p. 1-21, 2016.

SILVA, T. E. M.; BERNARDINELLI, S.; SOUZA, F. F.; MATOS, A. PEREIRA; ZUIN, V. G. Desenvolvimento e Aplicação de Webquest para Ensino de Química Orgânica: Controle Biorracional da Lagarta-do-Cartucho do Milho. Química Nova na Escola, v. 38, p. 47-53, 2016.

TÜRCKE, Christoph. Sociedade excitada: filosofia da sensação. Trad. Antônio Zuin, Fabio Durão, Francisco Fontanella e Mario Frungillo. Campinas: Unicamp, 2010.

WECKERT, John (Orgs.). Nanoethics - the ethical and social implications of nanotechnology. New Jersey: John Wiley \& Sons, 2007, p. 277-290. 
ZANDONAI, D. P.; SAQUETO, K. C.; ABREU, S. C. S. R.; LOPES, A. P.; ZUIN, V. G. Química Verde e formação de profissionais do campo da química: relato de uma experiência didática para além do laboratório de ensino. Rev. Virtual Quim., v. 6, n. 1, 73-84, 2014.

ZUIN, Vânia G. A inserção da dimensão ambiental na formação de professores de Química. Campinas: Átomo, 2011.

ZUIN, V. G.; ZUIN, A. A. S. A formação no tempo e no espaço da internet das coisas. Educação e sociedade, v. 37, p. 757-773, 2016.

Submetido em 06/05/2016

Aprovado em 20/03/2017

\section{Contato:}

Vânia Gomes Zuin

Departamento de Química, Universidade Federal de São Carlos

Rod. Washington Luís km 235 - SP-310

CEP 13.565-905 - São Carlos, SP -Brasil

Telefone: (16) 3351-8206 - FAX 3351-8350

Caixa Postal 676. 